\title{
Stages and Fracture Mechanisms of Lamellar Pearlite of 100-m-Long Differentially Hardened Rails Under Long-Term Operation Conditions
}

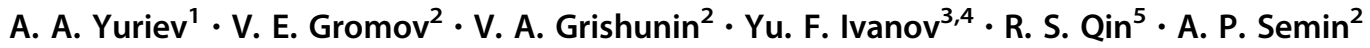

Received: 3 January 2018/Revised: 2 April 2018/Published online: 28 September 2018

(C) The Chinese Society for Metals and Springer-Verlag GmbH Germany, part of Springer Nature 2018

\begin{abstract}
Using the methods of transmission electron microscopy, the carbide phase evolution in surface layers of the differentially quenched rails is studied after the passed tonnage of 691.8 million tons at the depth up to $10 \mathrm{~mm}$ along the central axis and fillet of rail head. The action of two mutual supplement mechanisms of steel carbide phase transformation in surface layers at rail operation is established: (1) cutting mechanism of cementite particles with the following departure in the volume of ferrite grains or plates (in pearlite structure); (2) cutting mechanism and following dissolution of cementite particles, transfer of carbon atoms on dislocations (in Cottrell atmospheres and dislocation cores), transfer of carbon atoms by moving dislocations into ferrite grains volume (or plates) with the following repeated formation of nanosized cementite particles. The first mechanism is accompanied by the change in linear sizes and morphology of carbide particles. Cementite element composition change is not essential. Carbide structure change can take place during the second mechanism.
\end{abstract}

Keywords Cementite $\cdot$ Pearlite $\cdot$ Fracture $\cdot$ Rails $\cdot$ Mechanisms $\cdot$ Operation

\section{Introduction}

The steels with pearlite structure, which are widely used in industry in manufacturing of critical parts and structures, are the focus of scientists' attention in the field of physical material science because the structural phase changes affecting negatively the parts' reliability occur in steels under service conditions.

The processes of formation and evolution of structural phase state and properties of rail surface layers under long service conditions represent a complicated complex of interrelated scientific and technical problems. The

Available online at http://link.springer.com/journal/40195

V. E. Gromov

gromov@physics.sibsiu.ru

1 LTD Evraz - Integrated West Siberian Metallurgical Combine, Novokuznetsk, Russia

2 Siberian State Industrial University, Novokuznetsk, Russia

3 National Research Tomsk Polytechnic University, Tomsk, Russia

4 Institute of High Current Electronics SD RAS, Tomsk, Russia

5 School of Engineering and Innovation, The Open University, Walton Hall, Milton Keynes MK 7 6AA, UK importance of information in this field is determined by the depth of understanding of fundamental problems of solid state physics, and the practical importance of the problem.

In the modern conditions of high loads on axis and speeds of movement, the rail surface layers undergo the severe plastic deformations under long service conditions resulting in the formation of structural phase states with atypically high microhardness and nanoscale grain sizes. In a relatively small number of papers [1-6], it is shown that already after the passed tonnage of 100-300 million tons, the cementite plates are either bent or fractured, and the extremely high dislocation density is observed at the interphase boundaries; cementite dissolution and austenite formation occur at the expense of the reverse $\gamma \rightarrow \alpha$ transformation [1-6].

Under severe plastic deformation corresponding to $3.6 \times 10^{6}$ tons brutto of the passed tonnage, the formation of structure-free regions to the depth of $100 \mu \mathrm{m}$ is noted in rail surface layers. The microstructure of the "white" layers is similar, in many respects, to the structure being observed in the conditions of severe plastic deformation under equal channel angle pressing and shear torsion [7]. The determination of nature and evolution laws of carbide phase in the head of rails under long-term operation conditions is of high priority and practical importance. 
The majority of the used techniques of cementite phase evolution analysis lack the enough degree of locality. It does not permit to observe the evolution of the plate taken individually. Transmission electron microscopy (TEM) is the most developed method of careful analysis of structural phase state of a material to date. This method enables to carry out simultaneously the complex analysis of the morphology and defect structure (the light-field image), phase composition (dark field combined with imaging and indexing of electron diffraction patterns) with the enough (for the problem being analyzed in the paper) degree of locality [8].

The purpose of the research is to determine and analyze the evolution mechanisms of carbide phase in rails under long service conditions by layer-by-layer TEM.

\section{Experimental}

The samples of differentially hardened rails DT 350 manufactured at the joint stock company "EVRAZ-WSMC" after the passed tonnage of 691.8 million tons brutto at the experimental ring JSC "VNIIZhT" were used as the test material. According to the classification given in the literature [9], it corresponds to the severe plastic deformation. In the content of all chemical elements revealed as a result of the verifying analysis of chemical composition of rail metal, it satisfies the requirements of Russian Standard R 51685-2013 (Table 1).

The study of phase composition and defect substructure of rails was carried out by electron diffraction microscopy [10-14]. The test foils were manufactured by electrolytic thinning of plates cut out by electric spark method at the distance of 0,2 and $10 \mathrm{~mm}$ from the tread surface along the central axis and along the fillet (Fig. 1). The details are presented in Ref. [15].

\section{Results and Discussion}

The estimation of quality after the long service conditions showed that by the level of the mechanical properties (Table 2), the content of nonmetallic inclusions, macroand microstructures, the quality of metal satisfied the requirements of Russian Standard R 51685-2013 for rails of DT 350 category. The main morphological components

Table 1 Chemical composition of rails (wt $\%, \mathrm{Fe}$ the balance)

\begin{tabular}{llllllllll}
\hline $\mathrm{C}$ & $\mathrm{Mn}$ & $\mathrm{Si}$ & $\mathrm{Cr}$ & $\mathrm{Ni}$ & $\mathrm{Al}$ & $\mathrm{V}$ & $\mathrm{N}$ & $\mathrm{S}$ & $\mathrm{P}$ \\
\hline 0.77 & 0.87 & 0.34 & 0.08 & 0.06 & 0.08 & 0.08 & 0.01 & 0.022 & 0.081 \\
\hline
\end{tabular}

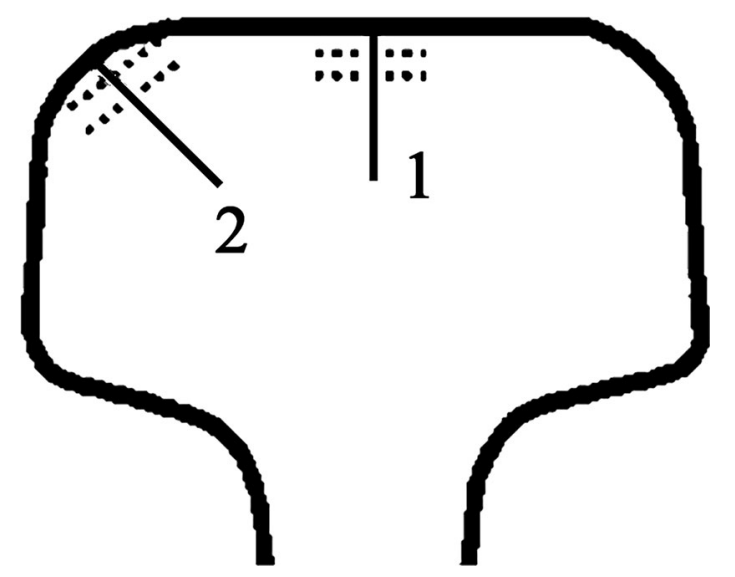

Fig. 1 Diagram of rail sample preparation when studying its structure by methods of optical and electron diffraction microscopy. The solid lines designate the directions along the central axis 1 and the fillet 2; the dotted lines designate the sites of location of metal layers used for foils preparation $(0,2$ and $10 \mathrm{~mm}$ from the surface)

of rail steel are the lamellar pearlite grains, the grains of ferrite-pearlite mixture and the grains of structurally free ferrite (Fig. 2).

The relative grain content of structurally free ferrite amounted to $5 \%$ (note that the relative content of ferrite grains is practically independent of the distance to the tread surface) at $10 \mathrm{~mm}$ distance from tread surface; the grains of ferrite-carbide mixture-5\%; the balance-pearlite grains. At $2 \mathrm{~mm}$ distance from tread surface, the relative content of grains of ferrite-carbide mixture increased by $10 \%$ in the surface layer (the layer adjacent to tread surface), which amounted to $35 \%$. It is evident that these transformations of the structure were realized at the expense of fracture of lamellar pearlite grains. The studies of structural morphology of rails' surface layer showed that the relative content of pearlite grains, where the lamellar structure is retained, amounted to $25 \%$; the balancepearlite grains in which the cementite plates were cut into separately located particles by the sliding dislocations. These particles have the globular shape, and their average sizes range within $30-50 \mathrm{~nm}$.

Two mechanisms of cementite plate fracture under deformation of pearlite structure steel are mainly discussed in scientific literature [16-24]. The first mechanism consists in the cutting of the plates by moving dislocations and carrying out the carbon atoms by them to ferrite by dislocation stress field. Estimations given in the research [16] show that in this case the maximum effect of cementite disintegration cannot increase the tenth parts of a percent from the available quantity of cementite.

The second mechanism consists in the pulling of carbon atoms by dislocations from the carbide phase lattice with the formation of Cottrell atmospheres due to the substantial difference of average energy of carbon atom bonds with 
Table 2 Mechanical properties of rails after the passed tonnage of 691.8 million tons

\begin{tabular}{|c|c|c|c|c|c|}
\hline Material & $\begin{array}{l}\text { Yield } \\
\text { point } \\
(\mathrm{MPa})\end{array}$ & $\begin{array}{l}\text { Ultimate } \\
\text { strength } \\
(\mathrm{MPa})\end{array}$ & $\begin{array}{l}\text { Elongation } \\
\text { unit per } \\
\text { length }(\%)\end{array}$ & $\begin{array}{l}\text { Contraction } \\
\text { ratio }(\%)\end{array}$ & $\begin{array}{l}\text { Impact toughness } \\
\text { at temperature } \\
+20{ }^{\circ} \mathrm{C}\left(\mathrm{J} / \mathrm{cm}^{2}\right)\end{array}$ \\
\hline DT 350 & 820 & 1270 & 11.5 & 40 & 34 \\
\hline $\begin{array}{l}\text { Requirements of Russian standard R 51685-2013 } \\
\text { for DT } 350 \text { category rails not less }\end{array}$ & 800 & 1180 & 9.0 & 25.0 & 15.0 \\
\hline
\end{tabular}
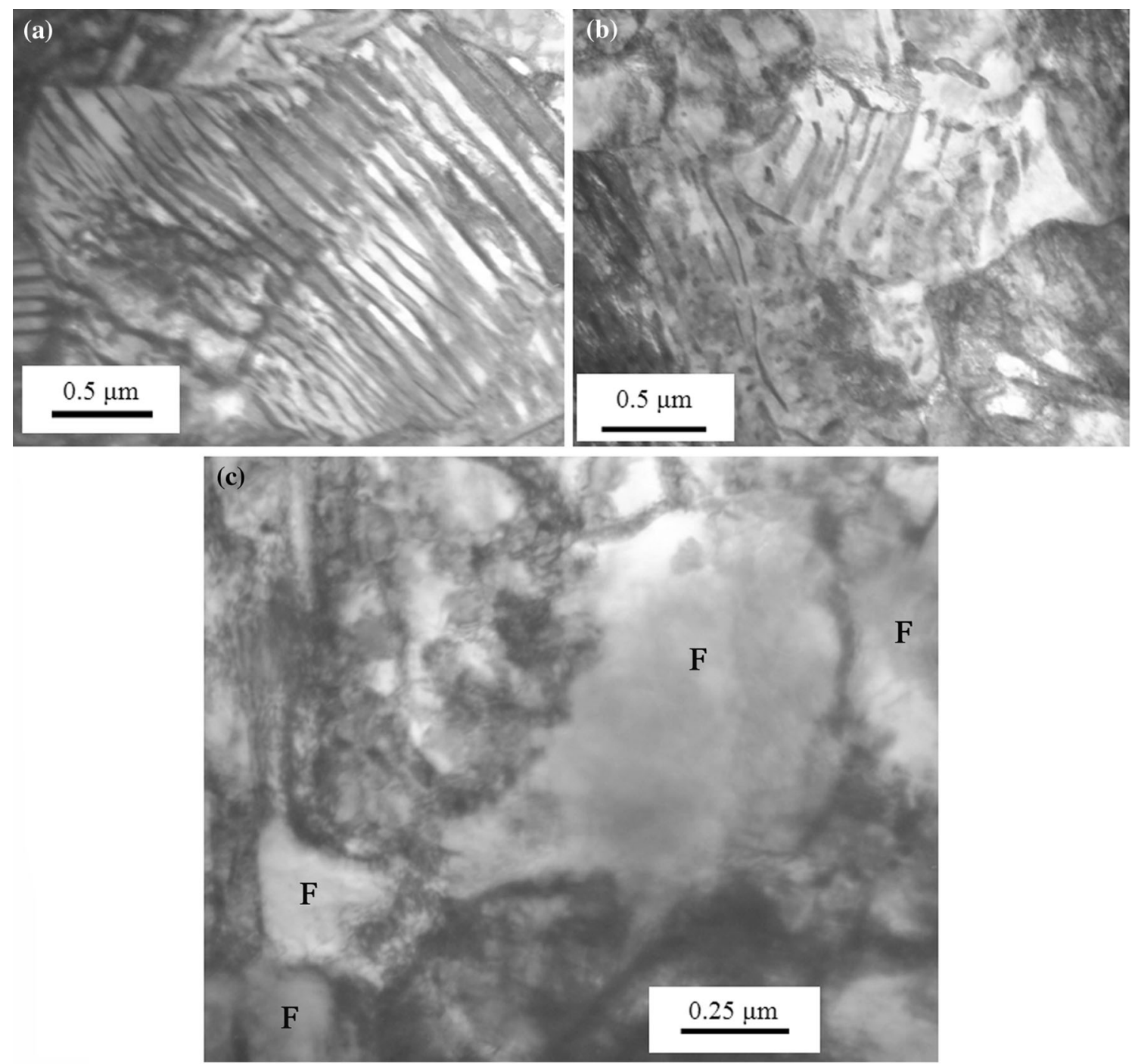

Fig. 2 TEM images of rail structure: a lamellar pearlite grains, $\mathbf{b}$ grains of ferrite-pearlite mixture, $\mathbf{c}$ grains of structurally free pearlite

dislocations $(0.6 \mathrm{eV})$ and atoms of iron in cementite lattice $(0.4 \mathrm{eV})$ in the plastic deformation process $[16,17,20]$. The diffusion of carbon occurs in the stress field formed by the dislocation substructure that is formed around the cementite plates. In this case, the degree of cementite disintegration must be determined by the value of dislocation density and the type of substructure. So, according to the author's opinion $[16,17]$ the model of cementite disintegration may be presented in the following way. The plastic deformation of pearlite steel causes the formation of cellular substructure with cells' boundaries located near the interphase boundary "cementite-ferrite." With the presence of thermodynamic stimulus (the bonding energy of carbon atoms with dislocations is higher than that with iron 
atoms in cementite), the carbon atoms, whose mobility is initiated by plastic deformation, are transferred from the cementite surface layers to the dislocations localized at the interphase boundary. It is indicative of simple connection between density and character of the dislocation distribution in ferrite, and the degree of cementite decay, confirming the dislocations' nature of the decay $[16,17]$.

The first process occurring by the mechanism of carbide particles cutting and pulling their fragments apart is accompanied only by the change in their linear sizes and morphology (Fig. 3). The change in the elemental composition of cementite in the process of fragmentation is minimal. During the occurrence of the second process (the action of the mechanism of dissolution "at the site") quite a different process is observed. At the initial stage of transformation, the cementite plates of pearlite colony are entangled by the sliding dislocations (Fig. 4a). It is accompanied by breaking the cementite plates into separate weakly disoriented fragments. Then, with increasing the degree of plastic deformation, the change in the carbide
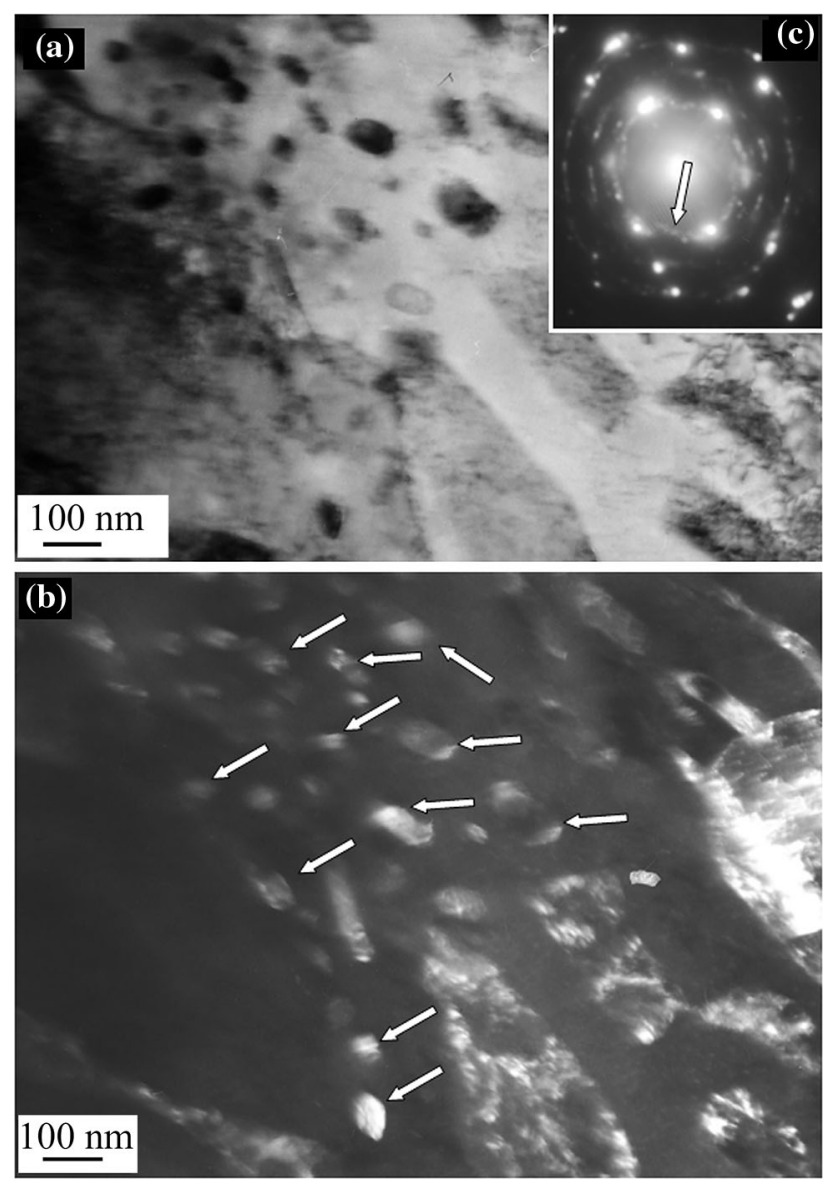

Fig. 3 Electron microscopy image of tread surface structure: a light field, b dark field obtained in reflection [012] $\mathrm{Fe}_{3} \mathrm{C}$, c the corresponding selected-area electron diffraction pattern, the arrow in $\mathbf{c}$ designates the reflection of obtaining of dark field $\mathbf{b}$; arrows in b designate cementite particles
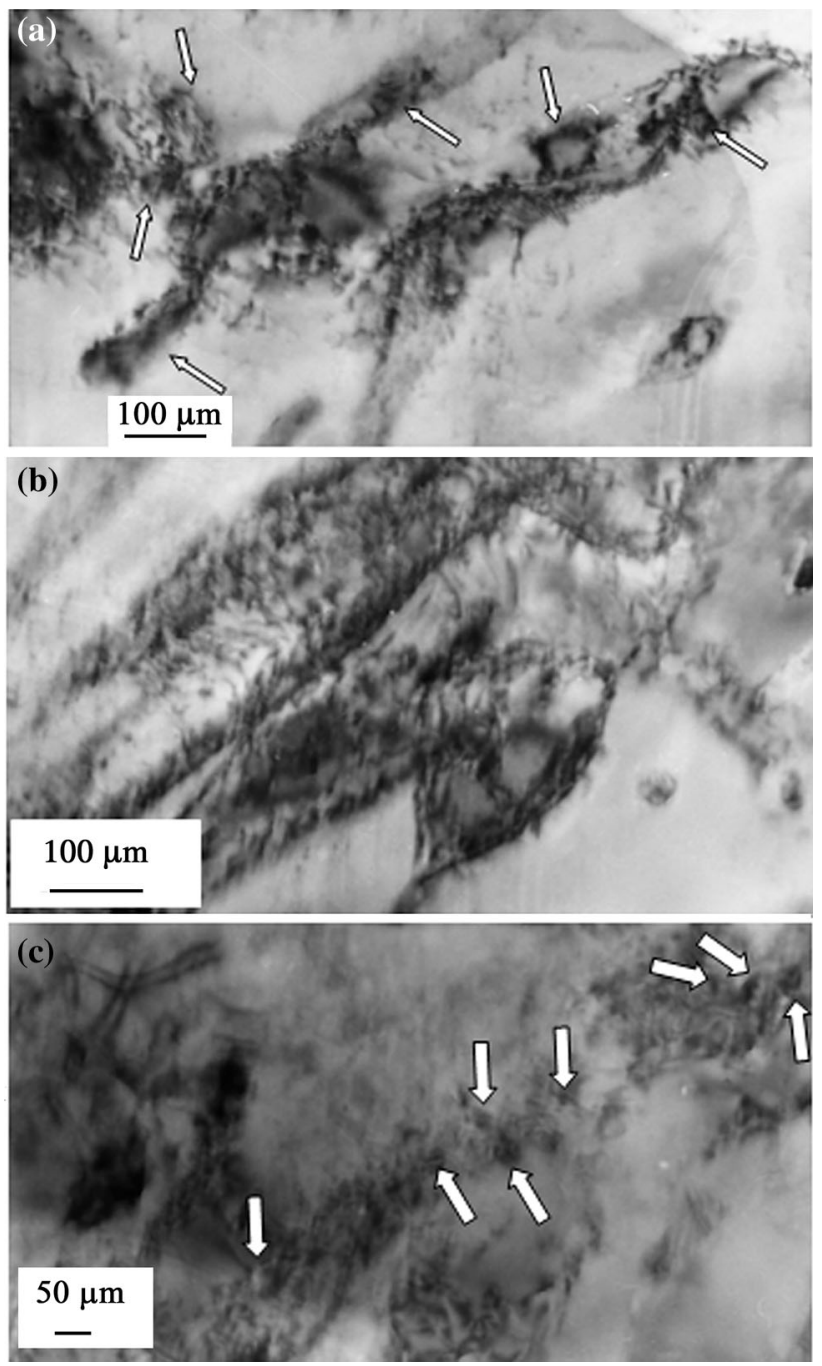

Fig. 4 TEM image of stages of transformation process of cementite plate of pearlite colony: a first stage, the arrows designate the fragments in cementite plates; $\mathbf{b}$ second stage being realized by mechanisms "at the site"; c third stage, the arrows designate the nanodimensional particles of carbide phase in the structure of cementite plates

structure may occur due to the pulling of the carbon atoms out of cementite lattice [25].

The second transformation stage of cementite plates of pearlite colony being realized by the mechanism of dissolution at the site and consisting in pulling the carbon atoms out the cementite crystal lattice is accompanied by the change in defect substructure of carbide, which is caused by the penetration of sliding dislocations from the ferrite crystal lattice to the cementite crystal lattice (Fig. 4b). Therefore, at this stage of cementite plates' dissolution, the interphase boundaries " $\alpha$-phase/cementite" play a particular role. The coherent and half-coherent boundary [18] facilitates the penetration of dislocations from $\alpha$-phase into cementite and inversely, and thereby, it favors the fracture 
and dissolution of carbide. The large-angle incoherent interphase boundary stabilizes the carbide structure and leaves the possibility only for the diffusion mass transfer. That is why, the cementite plates in pearlite colony break down and the spherical particles of cementite are retained at the boundaries of grains and subgrains.

At the next stage of cementite dissolution, the complete volume of the material, being occupied earlier by cementite plate, is filled by the nanodimensional particles. The characteristic image of the structure being formed in this case is shown in Fig. 4c. Moreover, the nanodimensional particles of carbide phase are observed in the ferrite matrix filling the interplate space of pearlite colonies. These particles may be carried out there in the process of dislocation sliding or, what is less probable, they formed in the process of deformation decay of carbon solid solution in iron crystal lattice.

In the literature $[8,25]$, the last stage of the cementite plate evolution under the severe plastic deformation of pearlite steel is revealed. It consists in the formation of disoriented quasiband structure on the base of $\alpha$-phase. The nanodimensional particles of iron carbide $\mathrm{Fe}_{4} \mathrm{C}$ are observed inside the bands and between them. Here, it is necessary to note that the nanodimensional particles of carbide $\mathrm{Fe}_{4} \mathrm{C}$ are most stable in $\alpha$-matrix with density of dislocations of $5.6 \times 10^{10} \mathrm{~cm}^{-2}$. Cementite and oversaturated (by carbon) carbide $\mathrm{Fe}_{20} \mathrm{C}_{9}$ are not formed in these conditions.

\section{Conclusion}

By methods of modern physical material science, the studies of structure, phase composition, defect substructure and the properties being formed at different distances along the central axis and the fillet in the head of 100-m-long differentially hardened rails after long service were carried out and the fracture mechanisms of lamellar pearlite were analyzed. It is shown that the long service life of rails is accompanied by the occurrence of two processes of structural transformation and the phase composition of lamellar pearlite colonies simultaneously: (1) the cutting of cementite plates and (2) the dissolution of cementite plates.

Acknowledgements The work was supported by Russian Scientific Foundation (Project No. 15-12-00010).

\section{References}

[1] Yu. Ivanisenko, H.J. Fecht, Steel Tech. 3, 19 (2008)

[2] Yu. Ivanisenko, I. Maclaren, X. Sauvage, R.Z. Valiev, H.J. Fecht, Acta Mater. 54, 1689 (2009)

[3] J.L. Ning, E. Courtois-Manara, L. Kurmanaeva, A.V. Ganeev, R.Z. Valiev, C. Kubel, Yu. Ivanisenko, Mater. Sci. Eng. A 581, 81 (2013)

[4] V.G. Gavriljuk, Mater. Sci. Eng. A 345, 81 (2003)

[5] Y.J. Li, P. Chai, C. Bochers, S. Westerkamp, S. Goto, D. Raabe, R. Kirchheim, Acta Mater. 59, 3965 (2011)

[6] V.G. Gavriljuk, Scr. Mater. 45, 1469 (2001)

[7] A.M. Glezer, Bull. Russ. Acad. Sci. Phys. 71, 1767 (2007)

[8] V.E. Gromov, E.V. Kozlov, V.I. Bazaikin, Fizika I mekhanika volocheniya i ob'emnoi shtampovki (Physics and Mechanics of Drawing and Die Forging) (Nedra, Moscow, 1997)

[9] A.M. Glezer, Deform. Fract. Mater. 2, 10 (2005)

[10] G. Thomas, M.J. Gorindge, Transmission Electron Microscopy of Materials (Intekst, Moscow, 1983), p. 320

[11] P. Hirsh, A. Hovy, P. Nicolson, Electron Microscopy of Thin Crystals (Mir, Moscow, 1968), p. 576

[12] F. Ray Egerton, Physical Principles of Electron Microscopy. An Introduction to TEM, SEM, and AEM (Springer, Berlin, 2005), p. 211

[13] C.S.S.R. Kumar (ed.), Transmission Electron Microscopy. Characterization of Nanomaterials (Springer, New York, 2014), p. 717

[14] C. Barry Carter, B. David, Transmission Electron Microscopy (Springer, Berlin, 2016), p. 518

[15] V.E. Gromov, A.B. Yuriev, K.V. Morozov, Y.F. Ivanov, $\mathrm{Mi}$ crostructure of Quenched Rails (CISP Ltd, Cambridge, 2016), p. 153

[16] V.G. Gavrilyuk, D.S. Gertsriken, Yu.A. Polushkin, V.M. Fal'chenko, Phys. Met. Metall. 51, 125 (1981)

[17] V.N. Gridnev, V.G. Gavrilyuk, Metallophizika 4, 74 (1992)

[18] R.F. Male, U.K. Hagel, Successes of Metal Physics (Metallurgia, Moscow, 1960), pp. 88-156

[19] N. Guo, B. Song, B.S. Wang, Q. Liu, Acta Metall. Sin. (Engl. Lett.) 28, 707 (2015)

[20] V.G. Gavrilyuk, Distribution of Carbon in Steel (Naukova Dumka, Kiev, 1987), p. 207

[21] O.M. Smirnov, V.A. Lazarev, Met. Phys. Phys. Metall. 56, 115 (1983)

[22] V.E. Gromov, A.A. Yuriev, Y.F. Ivanov, A.M. Glezer, S.V. Konovalov, A.P. Semin, R.V. Sundeev, Mater. Lett. 209, 224 (2017)

[23] V.E. Gromov, A.B. Yuriev, K.V. Morozov, Y.F. Ivanov, Microstructure of Quenched Rails (CISP Ltd, Cambridge, 2016), p. 155

[24] Y.F. Ivanov, V.E. Gromov, A.A. Yuriev, Fundam. Probl. Mod. Mater. Sci. 14, 297 (2017)

[25] Y.F. Ivanov, V.E. Gromov, N.A. Popova, S.V. Konovalov, N.A. Koneva, Strukturno-fazovie sostoyaniya i mekhanizmi uprochneniya deformirovannoi stali (Structure-Phase States and Strengthening Mechanisms of Deformed Steel) (Poligrafist, Novokuznetsk, 2016) 